\title{
Commercial productivity in the Fourth International Asparagus Cultivar Trial at Azul, Argentina (2016)
}

\author{
A.M. Castagnino ${ }^{1,2, a}$, K.E. Diaz ${ }^{1}$, W.J. Rogers ${ }^{1,3}$, M.B. Tarantino ${ }^{1}$, J. Marina ${ }^{1}$ and A. Guisolis ${ }^{1}$ \\ ${ }^{1}$ Centro Regional de Estudio de Cadenas Agroalimentarias (CRESCA), Universidad Nacional del Centro de la \\ Provincia de Buenos Aires (UNCPBA), Argentina; 2 Pontificia Universidad Católica Argentina (UCA) y ASAHO, \\ Argentina; ${ }^{3}$ CIC-BIOLAB AZUL, CONICET-INBIOTEC, CIISAS, Argentina.
}

\begin{abstract}
A field trial was carried out at Azul $\left(36^{\circ} 48^{\prime}\right.$, S lat. $59^{\circ} 51^{\prime}, \mathrm{W}$ long. O) consisting of asparagus hybrids 'Italo', 'Vittorio', 'Eros', 'Ercole', 'Giove', 'Franco', 'Chino', 'Early- California', 'UC-157', 'Patrón', 'NJ1189 ', 'NJ-1123' and 'NJ-1192', planted on 16/11/2011 with density 23.810 plants ha-1. Characters scored between 19/8/2016-17/11/2016 were: total fresh commercial productivity (TFCP), long and short spear fresh commercial productivity (LSFCP-SSFCP), total commercial spear number (TCSN), long and short commercial spear number (LCSN-SCSN), mean spear weight (MSW) and calibre distribution, CD (J: Jumbo; XL: Extra-Large; L: Large; M: Medium; S: Small y A: Asparagina). Spears were cut, selected (long: $22 \mathrm{~cm}$, short: $17 \mathrm{~cm}$ ), weighed, counted, washed and calibrated, and ANOVA-LSD ( $P \leq 0.05$ ) employed. Overall mean values were: TFCP:5 117, 10 tha-1, TCSN: 284910 spears and MSW: 18 g spear-1. For TFCP, 'Vittorio':6072, 'UC-157':6006, 'Eros':5885, 'Franco':5745, 'NJ-1123':5573, 'Early- California':5359 and 'NJ-1192':5284 kg ha-1 exceeded the mean. For LSFCP, 'UC- 157':4250a, 'Vittorio':4134ab, 'Franco':4056ab, 'Eros':3978ab, 'NJ1192 ':3861abc and 'Early-California':3744abc excelled and for SSFCP, 'NJ-1123':1985a, 'Vittorio':1983ab, 'Eros':1907abc, 'Italo':18174abcd, 'UC-157':1755abcde, 'Franco':1688abcde and 'Early- California':1615abcde. For TCSN, 'UC-157':356343, 'Patrón':341991, 'NJ-1192':324675, 'NJ1123 ':308022, 'Franco':307671, 'Early-California':307359, 'Vittorio':306306, 'Ercole':300027 and 'Eros':289497 exceeded the mean. For LCSN, 'UC-157':230334a, 'Patrón':219336ab, 'NJ1192 ':216996ab and 'Franco':200343abc excelled and for SCSN, 'NJ-1123':129012a, 'UC157':126009a, 'Patrón':122655a, 'Early-California':111345ab, 'Eros':110175ab, 'Ercole':110019ab, 'Vittorio':109317ab, 'Italo':108342ab, 'NJ- 1192':107679ab and 'Franco':107328ab. For CD, 48\% were larger calibres and $43 \%$ smaller; the following performed well for J: 'NJ-1189'a, 'Eros'ab, 'Giove'abc, for XL: 'Eros'a, for L: 'Franco'a, 'Eros'a, 'Ercole'a, 'Vittorio'ab, 'UC-157'ab, 'EarlyCalifornia'abc, 'NJ-1123' abc, for M: 'Ercole'a, 'UC-157'a, 'Patrón'ab, 'NJ-1123'abc, 'Franco'abc and for S: 'Patrón'a. From these results, it can be discerned that (i) a group of five hybrids ('Vittorio', 'Eros', and 'Franco' =Italian), and ('UC-157' and 'Early-California' =USA) were high performing for all three productivity measures (TFCP-LSFCP-SSFCP); (ii) an additional hybrid, 'Patrón', gave high spear number for all three measures (TCSN- LCSN-SCSN); (iii) the hybrids varied considerably in their calibre distribution; and (iv) the hybrids provided a range of different production options for existing and potential growers.
\end{abstract}

Keywords: Asparagus officinalis L. var. altilis, yield, spears, calibres, hybrids

\section{INTRODUCTION}

Asparagus (Asparagus officinalis L. var. altilis) represents a production alternative in countries, such as Argentina, in which arable crop production predominates and where horticultural production, commercialisation and consumption is restricted to only a few crops. In this country, more than $70 \%$ of the total volume corresponds to four species: potato $(40 \%)$, tomato (14\%), onion (12\%) and squash (7\%). Taking into account expanding

â-mail: amc@faa.unicen.edu.ar 
global and unsatisfied internal demands, as well as the crop's adaptation to the agroclimatic conditions in the central zone of the Province of Buenos Aires, asparagus comprises an attractive alternative for production diversification, which requires evaluation of the behaviour of different genotypes with the aim of determining the best adapted. To this end, trials carried out within the framework of the world network of asparagus trials allow this object to be met, as well as being able to compare the behaviour of the genotypes in other edaphoclimatic conditions.

The crop's life cycle can be divided into four stages: 1 ) early growth (1 $1^{\text {st }}$ and $2^{\text {nd }}$ year), of strong vegetative development; 2 ) increasing productivity ( $3^{\mathrm{rd}}$ and $4^{\text {th }}$ year), corresponding to the first harvestable years; 3 ) stable productivity (4th to $10^{\text {th }}$ years); and 4) decreasing productivity (from the $10^{\text {th }}$ year) (Giménez Azara et al., 2016). The economically active period reaches its productive maximum after four to five years (Asprelli et al., 2005). Given that in the early growth stage plantations are not yet productively stable and that numerous studies have demonstrated the existence of strong genotype-environment interaction that translates into different behaviours between the traditional varieties and even more so between the hybrids grown in distinct cultivation environments, study of the behaviour of different hybrids in the increasing productivity stage is desirable.

In Argentina, the cultivation of this species takes place in the following horticultural regions: VII, comprised of the Provinces of Buenos Aires and Santa Fe; VI, the Provinces of San Juan and Mendoza; V, the Province of Córdoba; I, the Province of Tucumán; and VIII, the Province of Río Negro (Santos, 2011).

Regarding spear length for commercial sale, $22 \mathrm{~cm}$ has traditionally been used, while currently leading countries in the commercialisation of the crop, such as Peru, have begun to commercialise a part of their production as short spears, commonly denominated "tips" $(10 \mathrm{~cm}$ in length) in bunches and trays, whose post-harvest behaviour is deserving of study (Giménez Azara et al., 2016). In Argentina, 22 and $17 \mathrm{~cm}$ are used for green asparagus, with the aim of minimising losses.

The general aim of this work is to evaluate the productivity of different genotypes of green and purple asparagus, in the framework of a trial included in the World Network of Asparagus Trials "4th-IACT" (Fourth International Asparagus Cultivar Trial), organised by the ISHS (International Society for Horticultural Science), as a form of contributing towards the expansion of the production and consumption of asparagus in Argentina and the promotion of the better positioning of the production companies in the market.

\section{MATERIALS AND METHODS}

A trial was carried out at the Experimental Field of the Faculty of Agronomía, Azul (36 $48^{\prime} \mathrm{S}$ lat., $59^{\circ} 51^{\prime} \mathrm{W}$ long.) of the National University of the Centre of the Province of Buenos Aires (Universidad Nacional del Centro de la Provincia de Buenos Aires - UNCPBA), consisting of the evaluation of the following hybrid genotypes: 'Italo', 'Vittorio', 'Eros', 'Ercole', 'Giove' and 'Franco' from Italy; 'Chino' from China; and 'Early-California', 'UC-157', 'Patrón', 'NJ-1189', 'NJ-1123' and 'NJ-1192' from the USA. The trial was planted on 16/11/2011 with a plant density of $23,810 \mathrm{ha}^{-1}$ spaced at $1.4 \mathrm{~m}$ between rows and $0.3 \mathrm{~m}$ between plants. The trial was a RCBD (Randomized complete block design) consisting of four blocks with rows $7 \mathrm{~m}$ long. Each block included 15 rows, each one of which corresponded to a plot with 27 plants, with the two lateral rows being guards. The paths between blocks were $4 \mathrm{~m}$ wide, while the header and lateral paths were of 5 $\mathrm{m}$, with the trial occupying a total area of $1690 \mathrm{~m}^{2}$.

The trial was carried out in a typical argiudol soil without profile impediments, with a slightly acidic $\mathrm{pH}$, normal electrical conductivity $(143.5 \mu \mathrm{S} \mathrm{cm}-1)$, moderate to good provision of total nitrogen (0.183\%); good provision of phosphorus (33.07 ppm, according to the method of Bray and Kurtz), 3.74\% organic material (Walkley and Black, 1934). The analyses were carried out by the Soil Analysis Laboratory of the Faculty of Agronomy-UNCPBA.

The study zone has a temperate climate, an annual mean temperature of $15^{\circ} \mathrm{C}$ (summer mean $22^{\circ} \mathrm{C}$, winter mean $8^{\circ} \mathrm{C}$ ) and an annual mean precipitation of $960 \mathrm{~mm}$.

Lot preparation for plantation was initiated various months before and consisted of 
the use of a disk crawler and a chisel plough. Prior to planting the lot was ploughed again, treated with a motocultivator and rows were cut to a depth of $0.25 \mathrm{~m}$.

Weed control consisted of a combination of motocultivator, hand-weeding and herbicide application. In pre-plantation, Trifluralina was applied at a dosage of $2 \mathrm{~L} \mathrm{ha}^{-1}$ and incorporated manually, followed by Linurón at $2 \mathrm{~L}$ ha-1. From the second year, a mixture of Metribuzín $\left(\mathrm{C}_{8} \mathrm{H}_{14} \mathrm{~N}_{4} \mathrm{OS} ; 0.5 \mathrm{~kg} \mathrm{ha}^{-1}\right.$ at 35\%) and Pendimetalín $\left(\mathrm{C}_{13} \mathrm{H}_{19} \mathrm{~N}_{3} \mathrm{O}_{4} ; 2.5 \mathrm{~L}\right.$ ha-1 at 31.7\%) was applied each year at pre-emergence, whereas at post-emergence a mixture of Glyphosate $\left(\mathrm{C}_{3} \mathrm{H}_{8} \mathrm{NO}_{5} \mathrm{P}\right)$ and Bentazon $\left(\mathrm{C}_{10} \mathrm{H}_{12} \mathrm{~N}_{2} \mathrm{O}_{3} \mathrm{~S}\right)$ was applied where necessary.

Complementary irrigation was carried out by weekly drip-feed during the first two years according to crop need.

Regarding plagues, it was not necessary to effect controls, since, during the monitoring applied during both the vegetative and productive stages, no plagues specific to asparagus were detected, only polyphagous species below the economic damage threshold of the crop. The following species were detected: Diabrotica speciosa and Chrysodina cuprescens (Coleoptera: Chrysomelidae); Dichelops furcatus and Piezodorus guildinii (Hemiptera: Pentatomidae); Phthia picta (Hemiptera: Coreidae) and Myzus persicae (Homoptera: Aphididae) and Trips tabaci (Thysanoptera: Thripidae) (Martinoia et al., 2015). Sometimes during the production stage the presence of the black cutworm Agrotis ipsilon and the common pill-bug Armadillium vulgare was detected, whose damage, consisting of perforations and boring at the base of the spears, did not affect their commercial quality, given that they were found below the height of the cut $(0.24 \mathrm{~m})$.

Regarding fertilisation, a background dosage of $250 \mathrm{~kg} \mathrm{ha}^{-1}$ of diammonium phosphate $\left(\left(\mathrm{NH}_{4}\right)_{2} \mathrm{HPO}_{4}\right)\left(\mathrm{FDA}, 180 \mathrm{~g} \mathrm{~kg}^{-1} \mathrm{~N}, 460 \mathrm{~g} \mathrm{~kg}^{-1} \mathrm{P}_{2} \mathrm{O}_{5}\right)$ was applied in bands of $0.30 \mathrm{~m}$, while annually urea $\left(\mathrm{CH}_{4} \mathrm{~N}_{2} \mathrm{O}\right)$ was broadcast during the vegetative period, with variable dosage depending crop phenology stage.

Thirty-nine manual harvests were carried out every other day between 19/8/2016 and $17 / 11 / 2016$. Harvesting and fresh processing was carried out following the methodology indicated by the quality green asparagus protocol of the Ministry of Agriculture of Argentina (Resolution-SAGPyA №249/2007).

The sampling unit per plot was 27 plants and, since there were four blocks in the trial, the total per hybrid was 108 . Once harvested, the spears were transported immediately to the processing laboratory.

The processing sequence was: washing, determination of total weight, determination of total spear number, cutting to $22 \mathrm{~cm}$ (long spears) and $17 \mathrm{~cm}$ (short spears), selection for quality, determination of commercial fresh weight, calibration of the commercial spears, determination of the number of spears per calibre and quantification of the defects in discarded spears and packaging. The commercial spears were classified in the following categories: according to their calibre (diameter $2 \mathrm{~cm}$ from the base): Small (S): 6-9 mm; Medium (M): 9-12 mm; Large (L): 12$16 \mathrm{~mm}$; Extra Large (XL): $16-18 \mathrm{~mm}$; Jumbo (J): $>18 \mathrm{~mm}$, as indicated by the quality protocol mentioned above.

Characters scored were: total fresh commercial productivity (TFCP), long and short spear fresh commercial productivity (LSFCP, SSFCP), total commercial spear number (TCSN), long and short commercial spear number (LCSN; SCSN), mean spear weight (MSW) and calibre distribution, CD (J: Jumbo; XL: Extra-Large; L: Large; M: Medium; S: Small and A: Asparagina). Spears were cut, selected (long: $22 \mathrm{~cm}$, short: $17 \mathrm{~cm}$ ), weighed, counted, washed and calibrated. Data analysis was by ANOVA-LSD ( $\mathrm{P} \leq 0.05)$.

\section{RESULTS}

Overall mean values were: TFCP: $5.12 \mathrm{t} \mathrm{ha-1}$, TNCT: 284,910 spears and MSW: $18 \mathrm{~g}$ spear1 , and $68 \%$ of the commercial production corresponded to long spears (Figure 1). 


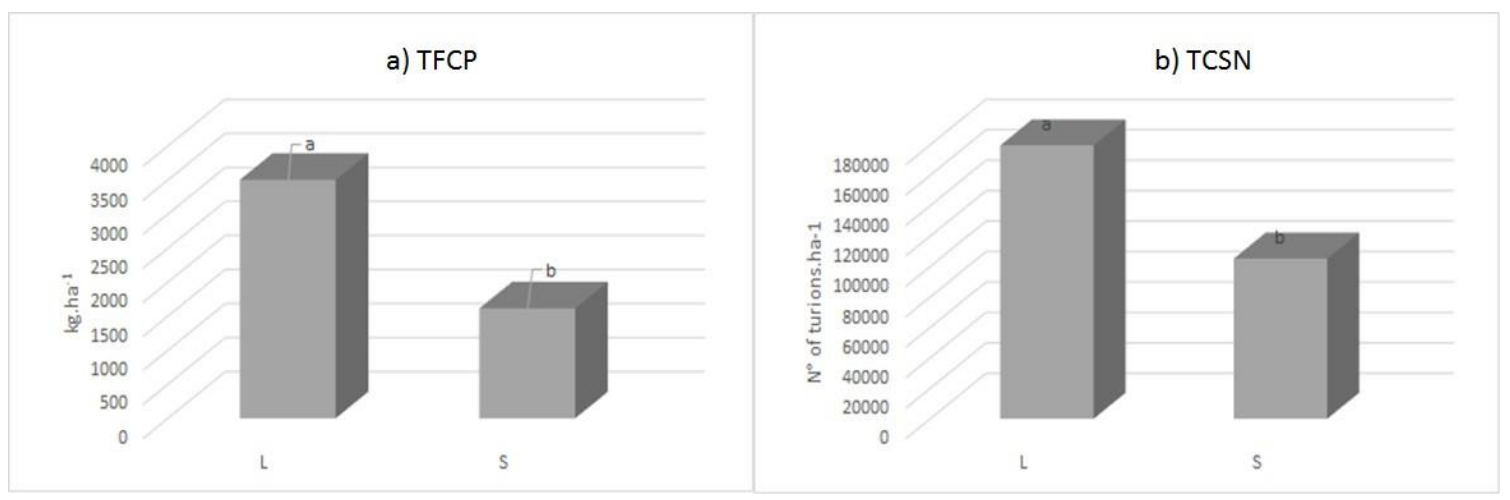

Figure 1. a) TFCP: Long (L) and short (S) mean total production of green and purple asparagus in the fifth production year after plantation. b) TCSN: Mean total long

(L) and short (S) spear number of green and purple asparagus in the fifth production year after plantation.

The commercial production obtained exceeded by $3.73 \mathrm{t} \mathrm{ha}-1$ that obtained in the first year evaluated (2012) and by $1.45 \mathrm{t} \mathrm{ha}^{-1}$ that in the second year. The number of spears ha-1 obtained showed a marked increase compared to that obtained in the first year, which was 26,116 commercial spears. Regarding the production achieved of different lengths and in spear number, the number of long spears ha-1 was 179,595 , while the number of short spears was 105,218 (Figure 1), meaning $63 \%$ of spears were of the long category.

Regarding the general mean weight per spear, the short spears weighed on average $21 \%$ less, with the long weighing $17.5 \mathrm{~g}$ and the short $15.33 \mathrm{~g}$. The following genotypes exceeded the mean: 'Vittorio': 6072; 'UC-157': 6006; 'Eros': 5885; 'Franco': 5745; 'NJ-1123':

5573; 'Early-California': 5359; 'NJ-1192': 5284 kg ha-1.

The following performed well for LSFCP: 'UC-157': 4250a; 'Vittorio': 4134ab; 'Franco': 4056ab; 'Eros': 3978ab; 'NJ-1192': 3861abc; 'Early-California': 3744abc; and the following for SSFCP: 'NJ-1123': 1985a; 'Vittorio': 1983ab; 'Eros': 1907abc; 'Italo': 18174abcd; 'UC-157': 1755abcde; 'Franco': 1688abcde and 'Early-California': 1615abcde (Table 1).

Table 1. Commercial spear production of green and purple asparagus of distinct lengths in the fifth year after plantation. SSFCP: Commercial productivity short spears; LSFCP: Commercial productivity long spears; TFCP: Total short and long spears; SCSN: Short spear number; LCSN: Long spear number; TCSN: Total spear number; MSW: Mean spear weight.

\begin{tabular}{|c|c|c|c|c|c|c|c|}
\hline Hybrid & $\begin{array}{l}\text { SSFCP } \\
\text { (t ha-1) }\end{array}$ & $\begin{array}{l}\text { LSFCP } \\
\text { (t ha-1) }\end{array}$ & $\begin{array}{l}\text { TFCP } \\
\text { (t ha-1) }\end{array}$ & $\begin{array}{l}\text { SCSN } \\
\left(\text { ha-1) }^{-1}\right)\end{array}$ & $\begin{array}{l}\text { LCSN } \\
\text { (ha-1) }\end{array}$ & $\begin{array}{l}\text { TCSN } \\
\left(\mathrm{ha}^{-1}\right)\end{array}$ & $\begin{array}{c}\text { MSW } \\
\text { (g spear-1) }\end{array}$ \\
\hline Italo & 1.82abcd & $3.28^{\mathrm{cd}}$ & 5.09 & $108342^{\mathrm{ab}}$ & $161655^{\mathrm{de}}$ & 269997 & 19 \\
\hline Vittorio & $1.94 a b$ & 4.13ab & 6.07 & $109317 \mathrm{ab}$ & $196989 \mathrm{bc}$ & 306306 & 20 \\
\hline Eros & $1.91 \mathrm{abc}$ & $3.98 \mathrm{ab}$ & 5.89 & $110175^{a b}$ & $179322^{\text {cd }}$ & 289497 & 20 \\
\hline Ercole & $1.52^{\text {cde }}$ & $3.59 \mathrm{bcd}$ & 5.11 & $110019 \mathrm{ab}$ & $190008^{b c d}$ & 300027 & 17 \\
\hline Chinese & $0.96^{f}$ & $2.30 \mathrm{e}$ & 3.26 & $59982^{d}$ & $111657^{f}$ & 171639 & 19 \\
\hline Early California & $1.61 \mathrm{abcde}$ & $3.74 \mathrm{abc}$ & 5.36 & $111345^{a b}$ & $196014 \mathrm{bc}$ & 307359 & 17 \\
\hline UC 157 & 1.76 abcde & $4.25^{a}$ & 6.01 & $126009 a$ & $230334 a$ & 356343 & 17 \\
\hline Giove & $1.41 \mathrm{de}$ & $3.04 d$ & 4.45 & $79638 \mathrm{~cd}$ & 141999e & 221637 & 20 \\
\hline Patron & $1.40 e$ & $3.32 \mathrm{~cd}$ & 4.71 & $122655^{a}$ & 219336ab & 341991 & 14 \\
\hline Nj 1189 & 1.56 bcde & $2.42^{\mathrm{e}}$ & 3.98 & $88179 b c$ & $110487 \mathrm{e}$ & 198666 & 20 \\
\hline Nj 1123 & $1.99 a$ & $3.59 \mathrm{bcd}$ & 5.57 & $129012^{\mathrm{a}}$ & $179010^{\text {cd }}$ & 308022 & 18 \\
\hline Nj 1192 & $1.42 \mathrm{de}$ & $3.86 \mathrm{abc}$ & 5.28 & 107679ab & $216996 \mathrm{ab}$ & 324675 & 16 \\
\hline Franco & 1.69 abcde & $4.06 \mathrm{ab}$ & 5.74 & $107328^{a b}$ & $200343 a b c$ & 307671 & 19 \\
\hline
\end{tabular}


The commercial production of first quality exceeded by $32.5 \%$ that obtained in the previous year, in which 32 harvests were carried out between 10/9/2015 and 10/11/2015 ( $P F C L=2034.64, P F C C=1830.87$ ), with the following cultivars exceeding the mean in PFC: 'Patrón' $=5265.7$; 'UC-157' $=4833.3$; 'Early-California' $=4617.7$; 'Eros' $=4282$ and 'Vittorio' $=4182 \mathrm{~kg}$ ha-1. In the same year, the production of spears was $30 \%$ less, with NTC $=218,850$ (NTCL=103,000; NTCC=116,100) and MSW=17.7 g spear-1, in which the following cultivars stood out: 'Patrón' $=331,000$, 'UC-157' $=304,670$; Early California $=255,000$ and 'Vittorio' $=226,000$ spears.

For the quantity of spears produced, 'UC-157', 'Patrón' and 'NJ-1192' performed particularly well, while the genotype that produced the least number, 'NJ-1189', also produced spears with the highest mean weight (Table 2).

Table 2. Calibre distribution for thirteen asparagus genotypes. Distinct letters between columns indicate significant differences at $\mathrm{P} \leq 0.05)$. Spear diameter $2 \mathrm{~cm}$ from the base with $\mathrm{S}: 6-9$ mm; M: 9-12 mm; L: 12-16 mm; XL: 16-18 mm; J: >18 mm.

\begin{tabular}{|c|c|c|c|c|c|}
\hline Genotype & $\mathrm{J}$ & $X L$ & $L$ & $M$ & $S$ \\
\hline Italo & $6006^{\text {def }}$ & $48984^{b c}$ & $92001^{a}$ & $73671^{\text {dd }}$ & $34008^{\text {def }}$ \\
\hline Vittorio & 11349 bcde & $11349^{b}$ & $88998^{a b}$ & $79677^{\text {bcd }}$ & $48984^{\text {cd }}$ \\
\hline Eros & $17004^{a b}$ & $71994^{a}$ & $98982^{a}$ & $70005^{d}$ & $25350^{\text {ef }}$ \\
\hline Ercole & $2652^{f}$ & $32331^{d e}$ & $91650^{a}$ & $99684^{a}$ & $47658^{c d}$ \\
\hline Chinese & $12012^{b c d}$ & $23985^{\mathrm{ef}}$ & $54327^{d}$ & $39312^{e}$ & $27651^{\mathrm{ef}}$ \\
\hline Early california & $10998^{\text {bcde }}$ & $37011^{d}$ & $82329 \mathrm{abc}$ & $78975^{\text {bcd }}$ & $55341^{b c}$ \\
\hline UC 157 & $7332^{\text {def }}$ & $36348^{d}$ & $88998^{a b}$ & $103350^{a}$ & $65676^{b}$ \\
\hline Giove & $13650^{a b c}$ & $52338^{b}$ & $69342^{\text {cd }}$ & $48984^{e}$ & $28314^{\mathrm{ef}}$ \\
\hline Patron & $5655^{\text {ef }}$ & $5655^{f}$ & $57993^{d}$ & 93639ab & $93015^{a}$ \\
\hline Nj 1189 & $18993^{a}$ & $40677^{\text {cd }}$ & $67665^{c d}$ & $45006^{e}$ & $19344^{f}$ \\
\hline Nj 1123 & $9672^{\text {cde }}$ & $54327^{b}$ & $84006^{\mathrm{abc}}$ & $90012^{a b c}$ & $68991^{\text {cd }}$ \\
\hline Nj 1192 & 11349 bcde & $36660^{d}$ & $71331^{\mathrm{bcd}}$ & $73983^{\text {cd }}$ & $68991^{b}$ \\
\hline Franco & $7332^{\text {def }}$ & $53352^{b}$ & $98982^{a}$ & $91650^{a b c}$ & $37011^{\text {de }}$ \\
\hline
\end{tabular}

For MSW, the best genotypes were, as well as 'NJ-1189', 'Giove', 'Eros' and 'Vittorio'. During the two previous years, the highest mean weight corresponded, in order of importance: 'Eros' (19.85); 'Giove' (19.64); 'Chino' (19.05); 'Italo' (18.63); 'Vittorio' (18.50); 'Franco' (18.26) and 'Early-California' (18.11) g spear-1, indicating a difference in the adaptation of certain genotypes under study in the stable productive stage compared to that of increasing production, demonstrating the importance of these types of study, with the aim of determining those with the best performance during the economic life of the plantations.

For TCSN, the following exceeded the mean: 'UC-157': 356343; 'Patrón': 341991; 'NJ1192': 324675; 'NJ-1123': 308022; 'Franco': 307671; 'Early-California': 307359; 'Vittorio': 306306; 'Ercole': 300027 and 'Eros': 289497 (Table 1). For LCSN, superior genotypes were: 'UC157': 230334a; 'Patrón': 219336ab; 'NJ-1192': 216996ab and 'Franco': 200343abc; and for SCSN: 'NJ-1123': 129012a; 'UC-157': 126009a; 'Patrón': 122655a; 'Early-California': 111345ab; 'Eros': 110175ab; 'Ercole': 110019ab; 'Vittorio': 109317ab; 'Italo': 108342ab; 'NJ-1192': 107679ab and 'Franco': 107328ab (Table 1). Regarding CD, the calibres were distributed as follows: J: 4\%; XL: 19\%; L: 31\%; M: 25\%; S: $15 \%$ and Asp: $6 \%$. The highest type of defect was ear sprouting with $67 \%$. For $C D, 48 \%$ were larger calibres and $43 \%$ smaller; the following were outstanding for J: 'NJ-1189'a; 'Eros'ab; 'Giove'abc; for XL: 'Eros'a; for L: 'Franco'a; 'Eros'a; 'Ercole'a; 'Vittorio'ab; 'UC-157'ab; 'Early-California'abc; 'NJ-1123'abc; for M: 'Ercole'a; 'UC157'a; 'Patrón'ab; 'NJ-1123'abc; 'Franco'abc and for S: 'Patrón'a (Table 2). For markets without rigorous demands regarding calibres, the results for 'Patrón', 'UC-157' and 'Early-California' were encouraging, while for those demanding larger calibres, 'Eros' and 'Vittorio' were more appropriate, since they gave a much higher proportion of these (65 and $58 \%$, respectively). 
Regarding the defects found, the main one observed was ear sprouting, manifest in the highest proportion in genotype 'NJ-1123' (a) and lowest in 'NJ-1192' (h), and apparent principally in harvests 28, $26(\mathrm{a}), 25(\mathrm{ab})$ and 27 (b). For defects caused by plagues, this was minimal and manifest in the smallest proportion in 'Vittorio', 'Chino', 'Franco', 'Giove' and 'Eros' (b). For the spears that had to be harvested very short for their tendency to open at low height, this defect was shown by 'Eros', 'NJ-1189' and 'Giove' (a) and mainly in harvests 28 and 29. Finally, other defects: crooked, hollow, sick, etc.) were shown by 'Giove' (a), 'Vittorio' (ab), Early, 'Italo' and 'Chino' (abc).

\section{CONCLUSIONS}

- For total productivity (TFCP), 'Vittorio', 'Eros' and 'Franco' (Italian) and 'UC-157', 'NJ1123', 'Early-California' and 'NJ-1192' (USA) outperformed the rest; six of these (all except ' $\mathrm{NJ}-1123^{\prime}$ ') were high performing for long spear production (LSFCP), whereas for short spear production, 'Italo' was included amongst the high performing group and 'NJ-1192' excluded. This means that a group of five genotypes ('Vittorio', 'Eros', 'Franco', 'UC-157' and 'Early-California') were high performing for all three productivity measures.

- For the measures of spear number, namely total (TCSN), long (LCSN) and short (SCSN), the genotype 'Patrón' was added to the above named genotypes for all three measures; plus 'Ercole' and 'Italo' performed well forSCSN.

- Hence there are several genotypes available that combine high productivity with high spear number.

- Regarding calibre distribution, 'Eros' was included amongst the best genotypes for the larger calibres (J, XL and L); taking into account the above results, this genotype combines high productivity and high spear number with higher calibre spears. In contrast, 'Patrón' produces more spears of the lower calibres (M and S); while it is not highly productive, it produces high numbers of spears of lower calibres.

- In conclusion, the genotypes tested provide a range of different production options for existing and potential growers of the crop.

\section{Literature cited}

Asprelli, P.D., López-Anido, F.S., and Cointry, E.L. (2005). Caracteres agronómicos en cultivares de espárrago de diferentes edades y manejos. Pesqui. Agropecu. Bras. 40 (1), 47-52 https://doi.org/10.1590/S0100- 204X2005000100007.

Giménez Azara, C., Castagnino, A.M., Dá z, K., Tarantino, M.B., and Rogers, W.J. (2016). Quinta evaluación de genotipos de espárrago en invernadero y respuesta a técnicas de envasado. Hortic. Argent. 35 (88), 16-35.

Martinoia, G., Castagnino, A.M., Otañ o, A.C., Wynne, M.J.Y., and Dáz, K.E. (2015). EL trips de las flores, Frankliniella occidentalis en híbridos de espárrago verde (Asparagus officinalis). Actas Congreso Argentino de Horticultura.

SAGPyA. (2007). Secretarıá DE Agricultura, Ganaderıá , Pesca Y Alimentos 2007. Protocolo de calidad para espárrago fresco. Resolución SAGPyA № 249/2007. http://www.alimentosargentinos.gov.ar/programa_calidad/ diferenciacion/sello/SAA010_Esparrago_v08.pdf.

Santos, B. (2011). Análisis económico del empleo de dos híbridos ('UC-157' y 'Italo') de espárrago verde con destino a diferentes mercados. Trabajo final, carrera de Ingenierí en Producción Agropecuaria. Facultad de Ciencias Agrarias. Pontificia universidad católica argentina (Buenos Aires), 19/12/2011.

Walkley, A., and Black, A. (1934). An examination of Degtjareff method for determining soil organic matter and a proposed modification of the chromic acid titration method. Soil Sci. 37 (1), 29-38 https://doi.org/10.1097/00010694-193401000-00003. 